\title{
ИНСТРУМЕНТЫ ПОЗНАНИЯ И ПРОГРЕСС
}

\author{
Н.П. Тишанинов \\ д.т.н., профессор, главный научный сотрудник управления \\ качеством технологических процессов в сельском хозяйстве \\ ФГБНУ «Всероссийский научно-исследовательский институт \\ использования техники и нефтепродуктов в сельском \\ хозяйстве», г. Тамбов
}

Управление научно-техническим прогрессом (НТП) обеспечива-

Meтоды, технологии, прогресс, эффективность, критерии, целевые функции, управление, производство

\section{Methods, technologies,} progress, efficiency, criteria, target functions, management, production ется оценкой решений на предпроектных и других этапах жизненного цикла технических систем. От объективности оценки зависит продуктивность решений и последующий успех прогресса. В прошлые десятилетия у нас в стране использовались организационные формы управления НТП с ослабленными экономическими интересами его участников и уравнительной системой оплаты труда. Этому уровню организации работы соответствовали и методы обоснования решений, основанные на унитарной нормативной базе данных («чтобы не заморачиваться»), которые приводили к огромным материальным потерям. В современных условиях конкурентной экономики, когда ответственность за средства на развитие НТП несоизмеримо выше, необходимы новые инструменты оценки решений. Поэтому создание методов оценки эффективности техники и технологий, включающих результативные критерии и адаптированных к этапам разработки и многообразию условий их использования, является актуальной задачей.

\section{Материалы и методы}

В работе использовались традиционные методы оценки эффективности техники и технологий, результаты наложения новых методов на оцениваемые технологические комплексы в различных регионах страны, методы хронометражных наблюдений и статистической обработки результатов.

\section{Результаты исследований}

В науке известны два основных средства познания - приборы для целей исследований и методы. Совершенствование или создание новых средств познания определяет научную новизну исследований. Достижения в этом направлении считаются реализованными, если новые или усовершенствованные средства познания обеспе- 
чивают повышение достоверности результатов исследования, позволяют расширить круг решаемых задач, сократить затраты на исследования. Других признаков успеха в этом направлении не существует [1].

Некоторые исследователи [2] указывают на существование других (специфичных) средств познания, научную классификацию автор считает способом познания. В ряде случаев с автором можно согласиться, когда логически выстроенная последовательность классифицирующих признаков обеспечивает исчерпывающую детализацию объекта исследований и осознанное формирование предпочтительных характеристик элементов объекта по определяющим признакам. Однако анализ практики применения этого способа познания свидетельствует о том, что у него отсутствуют критерии результативности. Уровень применения этого способа чрезвычайно размыт - в ряде случаев авторы схематично представляют объекты аналогичного назначения без видимых признаков созидательного процесса.

Некоторые авторы считают эффективным средством познания так называемые «прорывные теории». Вместе с тем теории, представляющие собой совокупность идей и взглядов, направленных на толкование сущности явлений, инструментом познания не являются. Но в случаях, когда теория формализована и структурирована до этапов выработки обоснованных решений, она становится инструментом познания. В этом случае теория превращается в метод, между теорией и методом существует функциональновременная связь [1].

Многие годы у нас в стране оценка эффективности техники и технологий производилась по приведенным затратам на единицу выполненных работ [3], которые определялись по формуле:

$$
3_{\text {пр }}=3_{\mathrm{T}}+0,15 \mathrm{~K}
$$

где 3 пр - приведенные затраты, приходящиеся на единицу выполненных работ, руб.;

$3_{\text {т }}$ - текущие эксплуатационные затраты, руб.;

0,15 - коэффициент эффективности капитальных вложений;

К - капитальные вложения, руб.

В текущие эксплуатационные затраты включали четыре основные составляющие - зарплата, затраты на ТО и ремонт, затраты на топливо (электроэнергию), амортизационные отчисления. Источником образования экономического эффекта, как правило, являлась первая составляющая, когда в технико-экономических обоснованиях планировалось создание машины или технологического комплекса большей производительности, чем производительность у базы сравнения. Расчёт остальных трёх составляющих эксплуатационных затрат базировался на нормативном методе, заимствованном из американской системы «стандарт-кост», разработанной экономистом Чартором Гаррисоном.

Такой метод выработки предпроектных решений, обоснования «Системы машин», решения задач использования машинных технологий в производстве предопределял одномерность развития научно-технического прогресса. Отраслевое развитие определялось планами создания техники и технологий с большей производительностью. Важнейшие потребительские свойства качество технологического процесса и надёжность технических систем нивелировались. Это явилось причиной отставания развития технологий и снижения эффективности производства.

Недостатки метода выработки решений в развитии научно-технического прогресса стали очевидными для всего общества. По данным Российской академии сельскохозяйственных наук, на внедрение первых трёх «Систем машин» для сельскохозяйственного производства было потрачено около 70 трлн рублей в современном денежном эквиваленте. При этом себестоимость сельскохозяйственной продукции возросла в разы, а производительность труда поднялась лишь на 9-15\%. В центральных газетах в 70-е годы прошлого столетия появились критические статьи о «гигантомании». Непрерывный рост размерных характеристик машин и технологических комплексов, обусловленный недостатками принятого метода обоснования решений, приводил к огромным экономическим потерям в использовании технического потенциала [4-6].

В 80-е годы в стране широко стали внедряться полнокомплектные кормоцехи КОРК-15 производительностью 15 тонн кормосмеси в час. При нормативной суточной загрузке по времени и производительности эти кормоцехи должны были обслуживать 6000 голов крупного рогатого скота, а в подавляющем большинстве хозяйств поголовье крупного рогатого скота было на порядок меньше, что предопределяло низкий уровень интенсивности использования этого дорогостоящего технологического комплекса.

Кроме того, для окупаемости капитальных вложений и текущих затрат на эксплуатацию КОРК-15 предполагалось включать в кормосмесь до 8 компонентов кормов. Только в этом случае достигалось условное повышение питательности 
кормосмеси, которое позволяло окупать эксплуатационные затраты. Однако в большинстве хозяйств в кормосмесь включали 2-3 компонента кормов, а загрузка по производительности и времени составляла 1,5-48\%, как показали обследования пяти регионов Центральной России. Уровень использования производства кормосмесей в хозяйствах был крайне убыточным.

По результатам всесоюзной инвентаризации в 1983 году в стране насчитывалось около 100 тыс. кормоцехов и кормокухонь. Если принять во внимание эти масштабы потенциального внедрения технологических комплексов с завышенными параметрическими данными и гарантированной отрицательной рентабельностью их использования в реальных условиях эксплуатации, то можно представить размер экономических потерь для страны.

Аналогичная ситуация по масштабам экономического ущерба сложилась с использованием зерноочистительных комплексов (78 тыс. шт.). При их разработке и производстве также игнорировались качество технологических процессов и техническая надёжность. В зерноочистительных технологиях отсутствовали средства управления массовыми потоками зерна, что исключало оптимальную загрузку основного технологического оборудования и приводило к значительным потерям полноценного зерна в фураж и отходы. Выход продовольственного зерна при использовании зерноочистительных агрегатов составлял около 60\%, агрегаты использовались за границами экономической эффективности.

Безответственная техническая рационализация при производстве зерноочистительных комплексов приводила к резкому снижению уровня технической надёжности. Из-за экономии материалов звёздочки приводов решетных станов стали размещать на гнутых кронштейнах, приваренных к корпусным деталям, что нарушало плоскостность размещения приводов, способствовало неоправданному росту биения рабочих органов и нарушению технологического процесса. Тоже направление рационализации ухудшало устойчивость опор промежуточного шнека, ослабляло корпус, что приводило к росту радиального биения и повышенному травмированию зерна. Это частные примеры безответственности, когда копейки экономили, а теряли миллиарды.

Упущение критериев эффективности и качества технологических процессов в методах выработки решений повлекло наибольшие экономические потери при создании и использовании агрегатов приготовления витаминной муки, которые внедрялись в огромных масштабах. Агрегат АВМ-0,65 сменили более производительными агрегатами ABM-1,5 и СБ-1,5. Основанием для такой замены также послужило сравнение затрат живого труда на единицу продукции, но никто не ставил задачу оценки окупаемости эксплуатационных затрат технологическими результатами.

Известно, что приготовление травяной муки не связано с получением дополнительных кормовых единиц - зелёнка высушивается, обеспечиваются лишь лучшие условия для сохраняемости корма. Однако на сушку зелёнки агрегат АВM-1,5 расходует 200 л дизельного топлива в час. Этих денег хватило бы на приобретение одной тонны зерна с последующим использованием на кормовые цели, кормовая питательность которого выше питательности витаминной муки, приготовленной за час эксплуатационного времени.

Нужно также учесть, что в технологии, кроме сушилки, работающей на дизтопливе, используется электропривод с установленной мощностью около 300 кВт, плюс затраты на зарплату операторам, на техническую эксплуатацию всего технологического комплекса, на производство зелёной травы (подготовка почвы, посев, уборка, перевозка и т.д.). Использование агрегатов для приготовления витаминной муки приносило огромные убытки хозяйствам, что ещё раз подчеркивает важность выбора средств обоснования решений в управлении научно-техническим прогрессом.

Длительное применение метода приведенных затрат для оценки эффективности техники и технологий на различных этапах научно-технического прогресса в нашей стране объясняется двумя причинами. В плановой экономике сохранялись устойчивые цены на товары и услуги, обеспечивались гарантии сбыта продукции, что создавало иллюзию реальности расчётных значений экономического эффекта. В плановой экономике для развития научно-технического прогресса расходовались бюджетные деньги, ответственность за которые у заказчиков и подрядчиков, мягко говоря, была пониженной, а использование упрощённых методов оценки заказов и последующих решений упрощали эти отношения.

Попытки включить в оценочные методы критерии эффективности и качества технологий предпринимались Н.М. Шаровым, М.В. Шахмаевым, Д.Н. Саакяном [7-9] и др., но повлиять на устои унитарного метода они не могли. Более того, предложения были не всегда обоснованными, но показательно настойчивыми. Например, 
Д.Н. Саакян предлагал учитывать качество работ методом «выравнивающей выработки», который заключался в том, чтобы машину с запасом показателей качества работы разрегулировать до уровня обеспечения качества работ на уровне базы сравнения и измерять разницу производительностей агрегатов.

При этом предполагается, что разрегулированная машина с сопоставимым уровнем качества работ относительно базы сравнения покажет более высокую производительность, и эту разницу в производительности автор предлагал включать в дополнительный источник образования экономического эффекта.

Необоснованность предложения объясняется следующим: трудно рассчитывать на воспроизводимость показателя качества с заданным уровнем за счёт регулировки; разрегулирование рабочих органов может привести не к увеличению выработки, а к снижению; чтобы установить экономические эквиваленты между качеством работ и выработкой, необходимо использовать специальные технологические исследования.

Альтернативой метода оценки эффективности техники и технологий с неполным калькулированием затрат или с нормативным методом их расчёта является метод с исчерпывающей калькуляцией затрат при использовании техники и технологий в конкретных условиях производства. При этом совокупную экономическую эффективность будут определять: научно-технический уровень оцениваемого объекта; \pm уровень его изготовления; \pm уровень его использования; \pm условия эксплуатации в конкретный промежуток времени; \pm квалификация обслуживающего персонала; \pm ситуация на рынке и т.д. При таком многообразии определяющих факторов сложно обеспечить условия сопоставимости и определиться с тем, что мы сопоставляем.

Недостатки этого подхода подтверждаются следующим. При формировании нормативной базы к системам технической эксплуатации машин и технологий согласно координационному плану исследований зональным институтам поручалось выполнить исчерпывающую экономическую оценку применения машин или технологий в конкретных условиях эксплуатации. В последующем эти результаты даже для квалификационной подготовки экспертов не удавалось использовать - слишком противоречивые были оценки в пределах одной группы машин.

Главный недостаток изложенных методических подходов заключается в отрыве оценки эффективности от конечных результатов технологий, от технологического эффекта. На основе предложений Дж. Мартино, Вебстера, Эриса [10] нами впервые было сформулировано понятие «технологический эффект».

«Технологический эффект» - полезный конечный результат от целевого применения технологических линий, комплексов и отдельных технических средств, проявляющийся (или предполагающий) в увеличении количества и качества продукции (услуг), снижении её потерь. Резервы повышения технологического эффекта на протяжении жизненного цикла машинной технологии представлены на рисунке 1.

С целью повышения результативности выработки решений на всех этапах научно-технического прогресса нами предложена методология оценки эффективности техники и технологий, основанная на сопоставлении текущих эксплуатационных затрат и технологических результатов (технологических эффектов). Классификация методов обоснования решений по механизации процессов и использования техники представлена на рисунке 2 (показана в символьной форме).

Классифицирующие признаки исходят из содержания выполненного анализа и основных идей, направленных на решение проблемы: по назначению; по способу оценки эффективности; по виду оцениваемой техники; по уровню принимаемых решений; по виду оцениваемого эффекта; по состоянию оцениваемых событий во времени; по уровню независимости оценок.

По назначению методы делятся: сравнение образцов техники на этапах её создания $(\mathrm{H} 1)$; выбор средств механизации технологических процессов (H2); обоснование реконструкции и частичной модернизации (Н3); повышение эффективности использования (H4). Деление методов по этому признаку позволяет разделять оценки и решения по этапам жизненного цикла техники.

По способу оценки эффективности: расчёт приведенных затрат на единицу работ (C1); расчёт суммы экономии приведенных затрат и технологического эффекта на годовую наработку (C2); расчёт показателя уровня использования потребительских свойств техники (С3); расчёт показателя уровня использования потребительских свойств техники и сроков работ (C4); соизмерение текущих эксплуатационных затрат с расчётным технологическим эффектом в единицу времени (С5); соизмерение текущих эксплуатационных затрат и потерь с действительным 


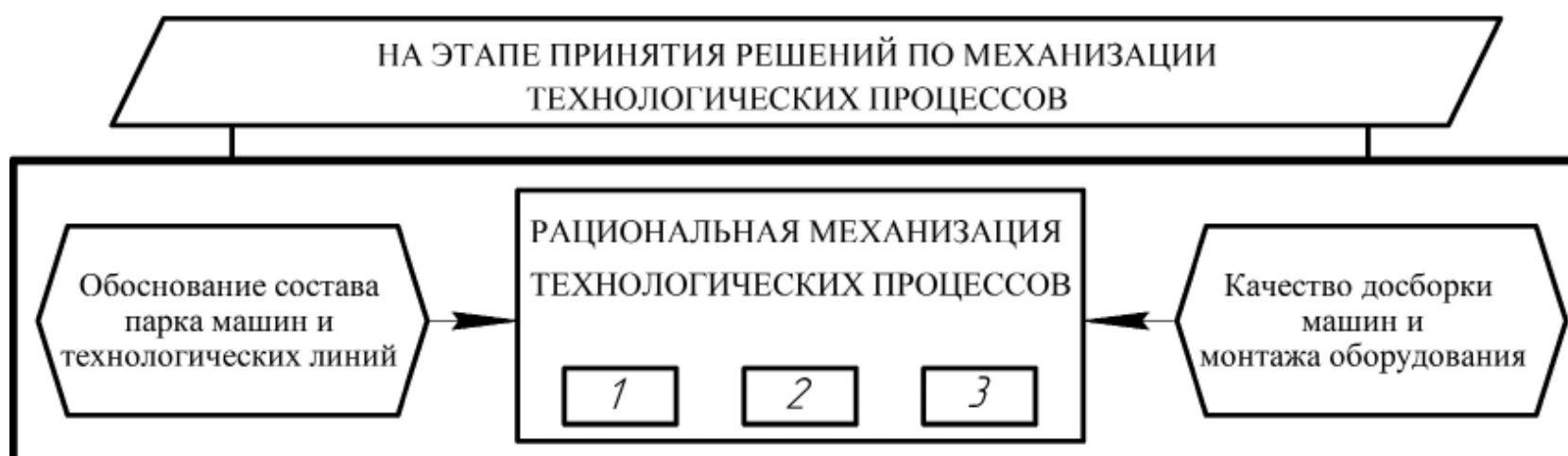

ФОРМИРОВАНИЕ ПАРКА МЕХАНИЗИРОВАННЫХ СРЕДСТВ ПРОИЗВОДСТВА С НЕОБХОДИМЫМИ ПОТРЕБИТЕЛЬСКИМИ СВОЙСТВАМИ
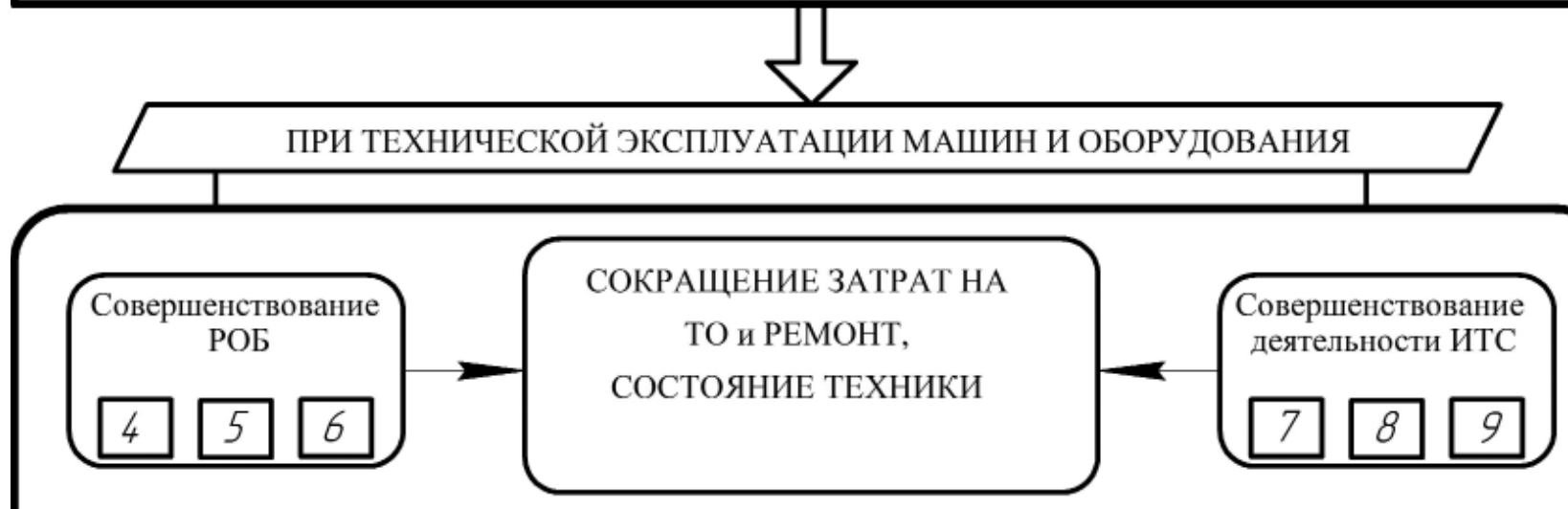

ПОДДЕРЖАНИЕ РАБОТОСПОСОБНОГО СОСТОЯНИЯ И ПОТРЕБИТЕЛЬСКИХ СВОЙСТВ

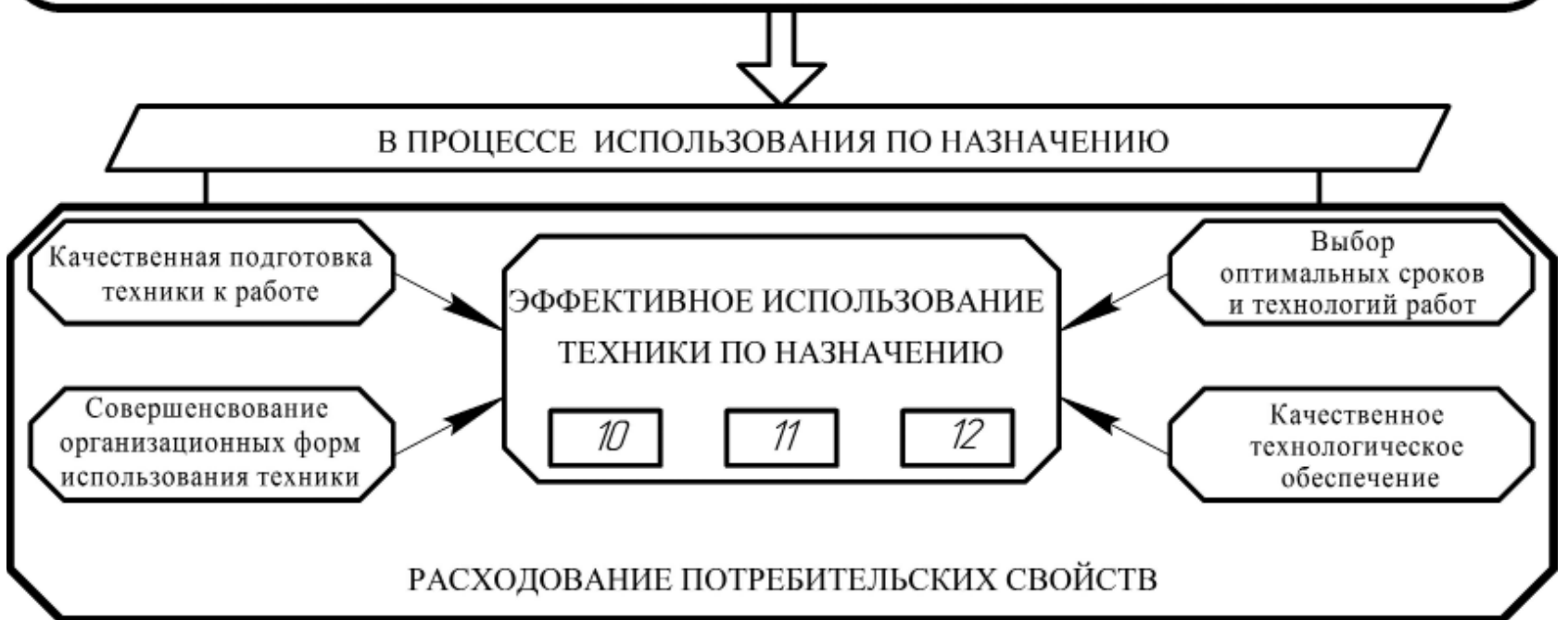

1 - частичная модернизация и переоборудование машин; 2 - реконструкция технологических линий; 3 - механизация вспомогательных процессов; 4 - улучшение оснащённости; 5 - рациональное размещение; 6 - эффективное использование; 7 - совершенствование оценки деятельности подразделений;

8 - совершенствование организационных форм службы; 9 - повышение квалификации; 10 - обеспечение качества работ; 11 - повышение производительности; 12 - экономия топлива и электроэнергии.

Рисунок 1 - Схема резервов повышения технологического эффекта 


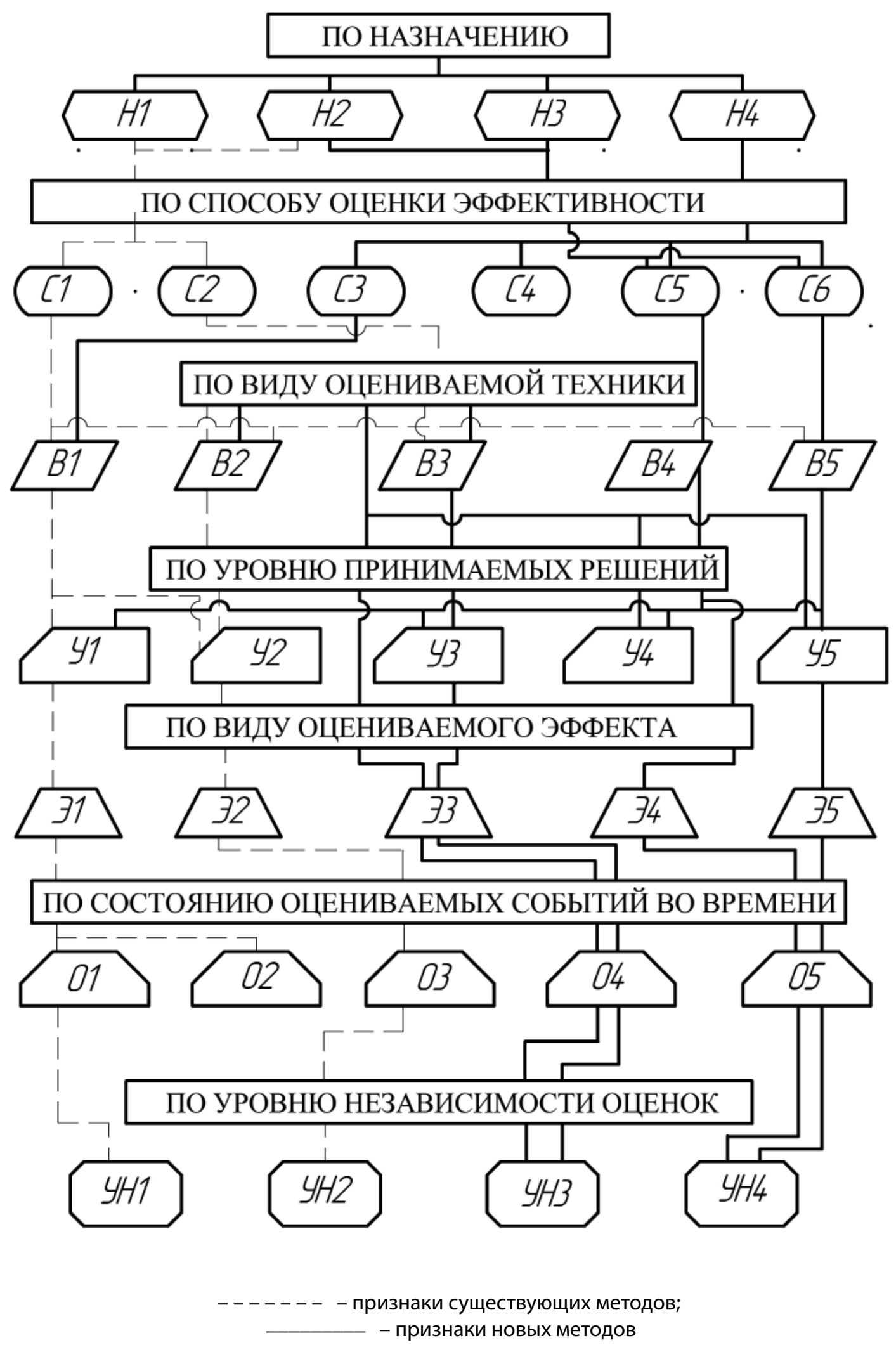

Рисунок 2 - Классификация методов обоснования решений по механизации процессов и использованию техники 
технологическим эффектом в единицу времени (С6). Сформулированные способы оценки эффективности в достаточной степени удовлетворяют многообразию решаемых задач и требованиям к критериям оценки, обусловленным отраслевой спецификой.

По виду оцениваемой техники: машиннотракторные агрегаты (В1); стационарные технологические линии (B2); группы агрегатов и мобильные технологические комплексы (В3); кормоцехи (B4); перерабатывающие комплексы (B5). Предложенная градация сельскохозяйственной техники отражает особенности технологических процессов, обеспечивает увязку со способами оценки эффективности. Деление по последним двум классифицирующим признакам указывает на необходимость создания специальных (неунитарных) методов.

По уровню принимаемых решений: перспективные (У1); на сезон (У2); на цикл работ (УЗ); ежесменно (У4); оперативные (У5). Деление методов по уровню принимаемых решений - необходимое условие результативности оценок и их практической ценности.

По виду оцениваемого эффекта: предполагаемый экономический, неполный (Э1); ориентировочный экономический, полный (Э2); опосредованный технологический, неполный (ЭЗ); расчётный технологический, полный (Э4); действительный технологический, полный (Э5). Порядок следования видов эффекта в классификации соответствует их возрастающей предпочтительности по полноте и объективности оценок. Этот классифицирующий признак имеет существенное значение для совершенствования существующих методов и создания новых.

По состоянию оцениваемых событий во времени: несостоявшиеся события (01); состоявшиеся совместно с несостоявшимися (O2); по завершении хозяйственного года, цикла производства (03); состоявшиеся в течение смены, за смену или цикл работ (04); состоявшиеся в течение смены и за любой период времени (O5). Достоинства методов по этому признаку исключительно важны, они определяют степень научной обоснованности комплексных оценок и принимаемых на их основе решений.

По уровню независимости оценок: смешение затрат на механизацию и эксплуатацию с промежуточными результатами (УН1); смешение затрат на механизацию и эксплуатацию, факторов производства с результатами (УН2); только уровень использования техники (УНЗ); эффективность механизации и эффективность использования раздельно и комплексно (УН4). Последний признак дополняет оценку методов, углубляет понимание необходимости их совершенствования и определяет область применения.

Предложенная методология адаптирована к основным задачам развития научно-технического прогресса: выбору предпочтительного варианта технологии; целенаправленному повышению её потребительских свойств; эффективному использованию в условиях производства. Методология предполагает использование результатов фундаментальных исследований агробиотехнологий для формирования исходной базы оценки технологических эффектов, что снижает риски развития ложных направлений прогресса.

В производстве достаточно сопоставить величину результирующего технологического эффекта $\left(Э_{\text {тг }}\right)$, получаемого за час основного времени работы, с часовыми эксплуатационными затратами (3 ${ }_{\text {эч }}$ ), чтобы убедиться в потенциальной эффективности технологии:

$$
\ni_{\mathrm{T} \Sigma}>3_{\text {эч }} ; \ni_{\mathrm{T} \Sigma}=\sum_{1}^{\kappa} \ni_{\mathrm{T}(+)_{\mathrm{i}}}-\sum_{1}^{n} \ni_{\mathrm{T}(-) \mathrm{j}},
$$

где $Э_{\mathrm{T}(+)_{i}} \ni_{\mathrm{T}(-) \mathrm{j}}$ - соответственно положительные и отрицательные технологические эффекты, руб./ч;

$\kappa, n$ - число соответственно положительных и отрицательных технологических эффектов, шт.

Ориентир эффективности технологии по годовой наработке определяется по формуле:

$$
\mathrm{H}_{\Gamma}=3_{\mathrm{A \Gamma}} /\left(\ni_{\mathrm{T} \Sigma}-3_{э ч}\right) \text {, }
$$

где $\mathrm{H}_{\Gamma}$ - граница экономической эффективности технологии по величине годовой наработки, ч/год;

$3_{\text {Аг }}$ - годовые амортизационные отчисления, руб.

Условием прибыльности используемой технологии в течение года будет:

$$
\mathrm{H}_{\phi}>\mathrm{H}_{\Gamma},
$$

где $\mathrm{H}_{\phi}$ - фактическая годовая наработка, ч.

Годовой экономический эффект можно определить по формуле:

$$
\ni_{\Gamma}=\left(\ni_{\mathrm{T} \Sigma}-3_{\mathrm{T}}\right)\left(\mathrm{H}_{\phi}-\mathrm{H}_{\Gamma}\right)
$$

Аналогичным путём определяются границы экономической эффективности по объёмам работ [4-6]. Предложенная методология и составляющие её критерии оценки вытекают из современных требований к управлению прогрессом на всех его этапах. 
Целевые функции управления производством:

$$
\left\{\begin{array}{l}
\mathrm{H}_{\phi} \rightarrow \max ; Э_{\text {г }} \rightarrow \max ; \\
\mathrm{H}_{г} \rightarrow \min =>\left(Э_{\text {т }}-3_{\text {тч }}\right) \rightarrow \max .
\end{array}\right.
$$

\section{Заключение}

При слабовыраженных экономических интересах участников производства в обществе используются невнятные организационные формы и инструменты управления научно-техническим прогрессом, экономика деградирует. Отраслевые структуры всех уровней при этом назывались «управлениями», хотя их функции к задачам управления производством отношения не имели.
Только участники производства с полноценными экономическими интересами и объединённые общей целью обязаны их (интересы) балансировать, исключать их конфликт и изыскивать резервы эффективности. Для этого необходимы продуктивные инструменты управления научно-техническим прогрессом, адаптированные ко всем его этапам. Создание новых инструментов особенно актуально в современных условиях, когда на рынке появляются технологии с принципиально разными способами реализации технологического процесса, что усложняет задачу выбора. Необходимы методы оценки по определяющим критериям с максимальной возможностью количественного сопоставления и вариативным учётом дополняющих критериев.

\section{Лumepamypa}

1. Большой энциклопедический словарь [Текст] / под ред. А.М. Прохорова. - М.: Большая Российская энциклопедия; СПб.: Норинт, 1997. - 1456 с.

2. Михайлова, Н.В. Организационно-методологическое единство и различия методов учета затрат и калькулирования себестоимости продукции [Текст] / Н.В. Михайлова // Изв. ВУЗов. Серия: Экономика, финансы и управление производством. - 2013. - № 2. - С. 69-75.

3. ГОСТ 23728-ГОСТ 23730. Техника сельскохозяйственная. Методы экономической оценки [Текст]. М.: Изд-во стандартов, 1988. - 25 с.

4. Тишанинов, Н.П. Методика оценки эффективности использования кормоцехов [Текст] / Н.П. Тишанинов, А.Ф. Волобоев // Механизация и электрификация сельского хозяйства. - 1987. - № 9. - С. 35-37.

5. Тишанинов, Н.П. Как повысить эффективность использования кормоцехов [Текст] / Н.П. Тишанинов, А.Ф. Волобоев // Техника в сельском хозяйстве. - 1987. - № 4. - С. 20-22.

6. Тишанинов, Н.П. Проблемы эксплуатации техники в рыночных условиях [Текст] / Н.П. Тишанинов // Механизация и электрификация сельского хозяйства. - 1994. - № 11. - С. 21-24.

7. Шаров, Н.М. Эксплуатационные свойства машинно-тракторных агрегатов [Текст] / Н.М. Шаров. - М.: Колос, 1981. - 240 с.

8. Шахмаев, М.В. Экономическая эффективность применения сельскохозяйственной техники [Текст] / М.В. Шахмаев. - М.: Россельхозиздат, 1983. - 207 с.

9. Саакян, Д.Н. Система показателей комплексной оценки мобильных машин [Текст] / Д.Н. Саакян. - М.: ВО «Агропромиздат», 1988. - 415 с.

10. Мартино, Дж. Технологическое прогнозирование [Текст]: пер. с англ. / Дж. Мартино. - М.: Прогресс, 1977. -591 c.

\section{References}

1. Bol'shoj jenciklopedicheskij slovar' [Tekst] / pod red. A.M. Prokhorova. - M.: Bol'shaja Rossijskaja jenciklopedija; SPb.: Norint, 1997. - $1456 \mathrm{~s}$.

2. Mikhajlova, N.V. Organizacionno-metodologicheskoe edinstvo i razlichija metodov ucheta zatrat i kal'kulirovanija sebestoimosti produkcii [Tekst] / N.V. Mikhajlova // Izv. VUZov. Serija: Jekonomika, finansy i upravlenie proizvodstvom. - 2013. - № 2. - S. 69-75.

3. GOST 23728-GOST 23730. Tehnika sel'skohozjajstvennaja. Metody jekonomicheskoj ocenki [Tekst]. - M.: Izd-vo standartov, 1988. $-25 \mathrm{~s}$.

4. Tishaninov, N.P. Metodika ocenki jeffektivnosti ispol'zovanija kormocehov [Tekst] / N.P. Tishaninov, A.F. Voloboev // Mehanizacija i jelektrifikacija sel'skogo hozjajstva. - 1987. - № 9. - S. 35-37.

5. Tishaninov, N.P. Kak povysit' jeffektivnost' ispol'zovanija kormocehov [Tekst] / N.P. Tishaninov, A.F.Voloboev // Tehnika v sel'skom hozjajstve. - 1987. - № 4. - S. 20-22.

6. Tishaninov, N.P. Problemy jekspluatacii tehniki v rynochnyh uslovijah [Tekst] / N.P. Tishaninov // Mehanizacija i jelektrifikacija sel'skogo hozjajstva. - 1994. - № 11. - S. 21-24. 
7. Sharov, N.M. Jekspluatacionnye svojstva mashinno-traktornyh agregatov [Tekst] / N.M. Sharov. - M.: Kolos, 1981. $-240 \mathrm{~s}$.

8. Shakhmaev, M.V. Jekonomicheskaja jeffektivnost' primenenija sel'skohozjajstvennoj tehniki [Tekst] / M.V. Shakhmaev. - M.: Rossel'hozizdat, 1983. - 207 s.

9. Saakyan, D.N. Sistema pokazatelej kompleksnoj ocenki mobil'nyh mashin [Tekst] / D.N. Saakyan. - M.: VO «Agropromizdat», 1988. $-415 \mathrm{~s}$.

10. Martino, Dzh. Tehnologicheskoe prognozirovanie [Tekst]: per. s angl. / Dzh. Martino. - M.: Progress, 1977. $-591 \mathrm{~s}$.

\title{
ОБЫЯВЛЕНИЕ
}

\author{
В ФГБОУ ВО Ярославская ГСХА в 2019 году издано \\ электронное учебно-методическое пособие в двух частях \\ «ЭЛЕКТРОСНАБЖЕНИЕ»
}

\author{
Авторы В.В. Шмигель, А.С. Угловский
}

2 электрон. опт. диска (CD-R)

В учебно-методическом пособии рассмотрены общие вопросы электроснабжения, представлены виртуальные лабораторные работы по дисциплине «Электроснабжение», разработанные в соответствии с программой курса для студентов бакалавриата по направлению «Агроинженерия», профиль «Электрооборудование и электротехнологии в АПК». Излагаемый материал сопровождается примерами и программами в Simulink, существенно облегчающими освоение курса электроснабжения.

Учебно-методическое пособие предназначено для студентов аграрных высших учебных заведений.

УДК 621.318; ББК 31.26; ISВN 978-5-98914-207-1

\section{ПО ВОПРОСАМ ПРИОБРЕТЕНИЯ ОБРАЩАТЬСЯ ПО АДРЕСУ: \\ 150042, г. Ярославль, Тутаевское шоссе, 58, ФГБОУ ВО Ярославская ГСХА e-mail: e.bogoslovskaya@yarcx.ru}

